\title{
Comparison of RIVA and infraclavicular block in forearm and hand surgery
}

\author{
Zubeyir Sivrikaya, ${ }^{1}$ Guldem Turan, ${ }^{2}$ Reyhan Cetiner, ${ }^{3}$ Dilek Subasi, ${ }^{3}$ \\ Gulcin Ozturk, ${ }^{4}$ Asu Ozgultekin, ${ }^{3}$ Osman Ekinci ${ }^{3}$ \\ ${ }^{1}$ Department of Anesthesiology and Intensive Care, Vakfikebir State Hospital, Trabzon, Turkey \\ 2Department of Anesthesiology and Intensive Care, Fatih Sultan Mehmet Training and Research Hospital, Istanbul, Turkey \\ 3Department of Anesthesiology and Intensive Care, Haydarpasa Numune Training and Research Hospital, Istanbul, Turkey \\ ${ }^{4}$ Department of Anesthesiology and Intensive Care, Kozan State Hospital, Adana, Turkey
}

\begin{abstract}
OBJECTIVE: The aim of this study was to compare 2 techniques that are widely used in hand, wrist, and forearm: regional intravenous anesthesia (RIVA) and infraclavicular brachial block.

METHODS: A total of 100 patients who were aged 18 to 85 years and who underwent hand, wrist, or forearm surgery of at least 30 minutes duration were included. RIVA was applied to Group 1 patients with administration of $40 \mathrm{~mL}$ of prilocaine (3 mg/kg). Ultrasonography-guided infraclavicular block was performed on Group 2 patients with $20 \mathrm{~mL}$ of $1 \%$ prilocaine. Several aspects of these 2 methods were compared, including length of time required to apply anesthesia, the analgesic effectiveness of the treatment during administration and in the peroperative and postoperative periods.
\end{abstract}

RESULTS: The rate of mild and complete sensory loss was significantly higher in Group 2 at $10^{\text {th }}$ and $15^{\text {th }}$ minutes than in Group 1. The number scoring less than grade 2 using modified Bromage grading system in Group 2 was considerably greater than in Group 1. Processing time to apply the block was significantly longer in Group 1 compared with Group 2.

CONCLUSION: It was determined that infraclavicular brachial block is superior to the RIVA method with respect to length of time required to administer and ease of application.

Keywords: Infraclavicular brachial block; regional intravenous anesthesia; upper extremity surgery.

$T$ he use of regional anesthesia techniques in surgical procedures continues to evolve and become more popular. Regional anesthesia is preferred to general anesthesia in suitable patients as a result of greater analgesic effectiveness in the pre- and postoperative periods, and lower peroperative morbidity, length of postoperative hospital stay, and cost.

Received: May 07, 2017 Accepted: July 04, 2017 Online:

Correspondence: Dr. Guldem TURAN. Fatih Sultan Mehmet Egitim ve Arastirma Hastanesi,

E 5 Bostanci, Isanbul, Turkey.

Tel: +90 216 - 5783000 e-mail: gturanmd@yahoo.com

(c) Copyright 2017 by Istanbul Northern Anatolian Association of Public Hospitals - Available online at www.kuzeyklinikleri.com 
Regional intravenous anesthesia (RIVA) is a preferred form of regional anesthesia, particularly in surgery of the upper extremities, performed with the injection of anesthetic solution into a local vein that is blocked with a tourniquet. RIVA is often used due to features such as minimal postoperative complications, low cost, and ease of application. However, there are a number of disadvantages to RIVA as well, including the need for a large volume of local anesthesia and short duration of anesthesia after release of the tourniquet.

Peripheral block applications have become more popular with the introduction of ultrasound (US) technology to the administration of anesthetic agents. As the anesthetic agent can be quickly and safely given to patients in US-guided peripheral block, the technique is now widely used in surgery that is of short duration on an extremity.

The aim of this study was to compare these 2 methods of anesthesia applied in hand, wrist, and forearm surgery: ultrasound-guided infraclavicular brachial block and RIVA.

\section{MATERIALS AND METHODS}

This study was conducted after obtaining approval from ethics committee of Haydarpasa Numune Teaching and Research Hospital, making the required explanations about the study to the patients, and finally, obtaining their informed consent. A total of 104 patients who were examined either in the orthopedics or plastic surgery clinic (American Society of Anesthesiologists [ASA] physical status classification I-III and body mass index $<35 \mathrm{~kg} /$ $\mathrm{m}^{2}$ ) who underwent hand, wrist, or forearm surgery of minimum 30 minutes and maximum $180 \mathrm{~min}$ utes duration were initially included in this study. Patients were excluded from the study if there was local anesthetic allergy or local infection in the area where block was to be applied, coagulopathy, neurological deficit in the upper extremity, prominent psychiatric or cognitive disorder, substance abuse, previous clavicular fracture or pneumonectomy, pregnancy, pneumothorax, thrombophlebitis, arteriosclerotic vascular disease, Raynaud's disease, arteriovenous fistula, scleroderma, sickle cell ane- mia, extensive burns, lacerations, or infection in the area to be operated on, or neuromuscular disease, such as myasthenia gravis, decompensated heart failure, or epilepsy. Non-cooperative, debilitated, or malnourished patients, and those with advanced liver dysfunction were also excluded from the study. Three patients who underwent RIVA procedure but needed an additional injection of local anesthetic agent due to development of pain at surgical site were also excepted. Moreover, 1 patient from Group 2 required general anesthesia and therefore was excluded from the study.

Patients were divided into 2 equal groups by simple randomization programmed by computer. Following intravenous line insertion, standard monitoring (noninvasive blood pressure, electrocardiography, oxygen saturation) was performed and all patients were sedated with midozalam $(0.03 \mathrm{mg} / \mathrm{kg})$.

Group 1 (RIVA) ( $n=50)$ : Vessel access points were opened on the back of the hand of the extremity to be operated on and on contralateral arm with 22-G needle. Intravenous access on operated extremity was used for RIVA application, while crystalloid infusion and drug solution were delivered through the other. The upper part of the operated arm was wrapped with cotton and doublecuff tourniquet was put in place. Before injection of the anesthetic agent, the arm was firmly wrapped from fingertips to distal tourniquet with $10-\mathrm{cm}$ wide elastic (Esmarch) bandage to drain the venous blood, and then proximal cuff tourniquet was inflated to $300 \mathrm{mmHg}$ pressure. Elastic bandage was removed and arterial circulation was confirmed by palpating the radial artery. The pre-prepared drug was administered intravenously to the operated arm in 90 seconds and then vessel access was closed. Distal tourniquet was inflated 10 minutes after drug administration while proximal tourniquet was deflated. In the postoperative period, the tourniquet was deflated at intervals beginning 35 minutes after the injection. Prilocaine was used as local anesthetic (40 $\mathrm{mL}$ of $3 \mathrm{mg} / \mathrm{kg}$ ).

Group 2 (infraclavicular block) $(\mathrm{n}=50)$ : The patient's head was turned to the opposite side of block application. The area where the block would be applied was disinfected with $10 \%$ povidone, and 
local anesthesia ( $2 \%$ lidocaine, $20 \mathrm{mg} / \mathrm{mL}$ ) was administered subcutaneously to region of peripheral nervous needle puncture. A peripheral nerve needle (21-G) with a length of 50-80 $\mathrm{mm}$ and linear probe (5-12 MHz) were used in block application. The probe was covered with a sterile, transparent cover, sterile gel was applied, and it was then sagittally placed $1 \mathrm{~cm}$ below the intersection of the clavicle and coracoid process.

Twenty $\mathrm{mL}$ of $1 \%$ prilocaine was administered around the subclavian artery and lateral, posterior, and medial cords with aspiration every $5 \mathrm{~mL}$ in correlation with the US image (in-plane technique). Sensory examination was performed every $5 \mathrm{~min}$ utes for 30 minutes after application of the block. Motor function was examined every 10 minutes. The first 3 fingers and wrist dorsal area were used for sensory examination of the radial nerve, while the fifth finger was used for the ulnar nerve. The first 3 fingers and volar aspect of the wrist were used for sensory examination of the median nerve, and the lateral region of the forearm was used for comparison of the musculocutaneous nerve with the nerves of the opposite forearm. Pinprick sensation test was performed in both groups using a scale for sensation block, and a modified Bromage scale was applied for assessment of the motor block. The results were noted as numbness, moderate, or no sensory block in pinprick sensation test.

Surgery commenced when an absence of sensation determined by pinprick test and a score of $\leq 2$ on modified Bromage scale was confirmed. Additional administration of local anesthesia to operated area, need for application of a rescue block on the distal part of the infraclavicular region, or application of general anesthesia was accepted as failure. Rescue block was applied when 1 or 2 nerves could not be blocked. If more then 2 nerves could not be blocked, general anesthesia was used. The number of times an invasive attempt was needed for block and whether vessel puncture occurred were also noted.

Process duration was defined in Group 1 (RIVA) as the period that started with application of the Esmarch bandage and ended with completion of the local anesthetic injection. In Group 2, (infraclavicular block) it was defined as the period between the passage of the peripheric nerve stimulator needle through the cutaneous and subcutaneous layers and the complete injection of local anesthesia. In addition, systolic blood pressure, diastolic blood pressure, mean blood pressure (MBP), heart rate (HR), and level of peripheral oxygen saturation were checked every 5 minutes from the initiation of the nerve blockade to postoperative $20^{\text {th }}$ minute and noted in order to monitor the hemodynamic state of patients. After the application of the blockade, patients were questioned as to comfort and satisfaction with the method of anesthesia application prior to undergoing surgery. They were also asked if they would prefer the same anesthetic method if another operation were necessary, and the responses were noted. Details of preoperative application of tourniquet, duration, and whether patients developed pain as a result were also recorded. Furthermore, the time patients needed first analgesic in the postoperative period was also noted. Finally, sensory and motor function examinations were performed at $2^{\text {nd }}, 4^{\text {th }}, 8^{\text {th }}$, and $24^{\text {th }}$ hours, and early complications were recorded.

\section{Statistical analysis}

IBM SPSS Statistics for Windows, Version 21.0 (IBM Corp., Armonk, NY, USA) software was used for the analyses. Mean \pm standard error and ratios of value frequency were used for definitive statistical analysis of data. The distribution of variables was assessed with the Kolmogorov-Smirnov test. Independent samples t-test and Mann-Whitney $U$ test were applied for the analysis of quantitative data. Both chi-square test and Fisher's exact test (when chi-square test could not be used) were used to analyze qualitative data. A minimum of $15 \mathrm{pa}$ tients per group was required for the comparison of blockade types to have $100 \%$ statistical power and $0.5 \%$ standard error.

\section{RESULTS}

One patient from Group 1 was converted to general anesthesia and 3 patients from Group 2 required additional local anesthesia due to pain that developed in the operated area. Therefore, these patients 


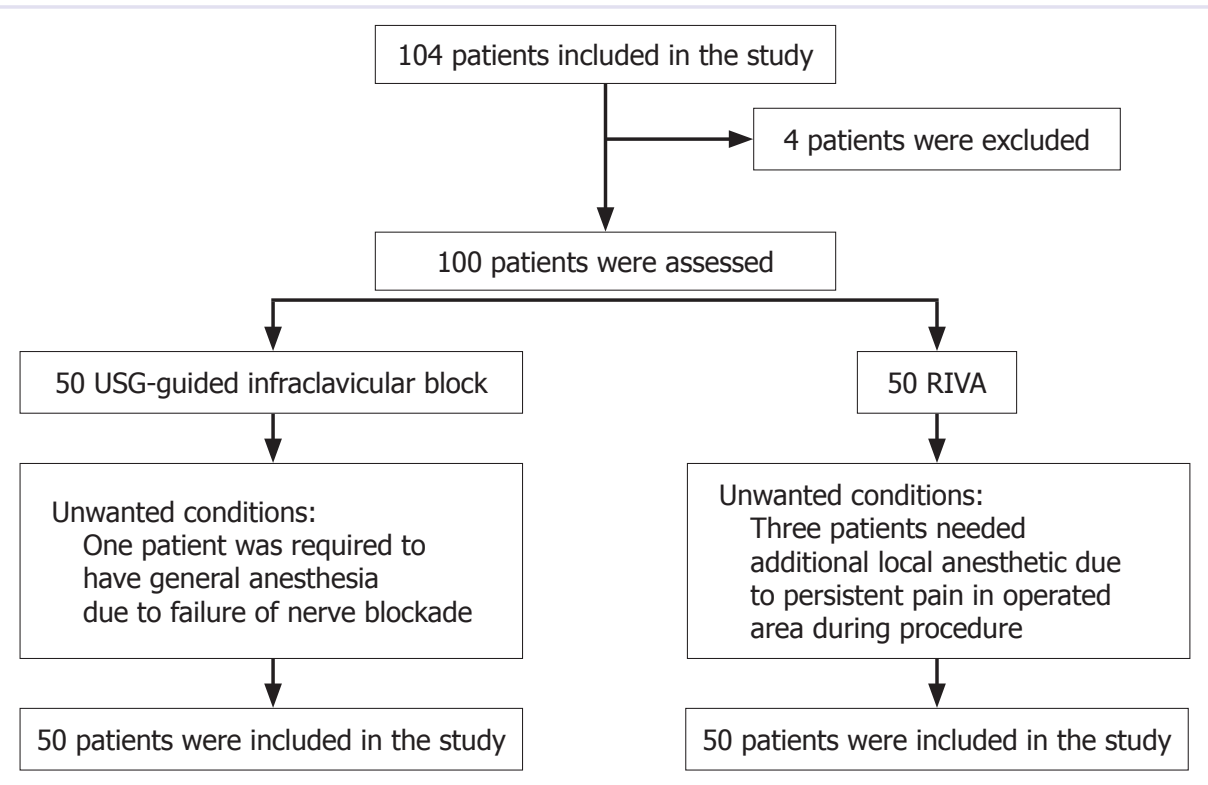

FIGURE 1. The flow chart of randomization. RIVA: Regional intravenous anesthesia.

were excluded from the study (Figure 1).

There was no significant difference between the groups in terms of mean age (Group 1:38.6 \pm 16.6 years, Group 2: $36.3 \pm 14$ years), weight (Group 1: $74.4 \pm 12.9 \mathrm{~kg}$, Group 2:77.2 $\pm 15.4 \mathrm{~kg}$ ), gender distribution (Group 1: 16 female/34 male, Group 2: 11 female/39 male), or ASA classification.

There was no significant difference between Group 1 and Group 2 in the evaluation of pinprick sensation at the fifth minute. Percentage of moderate sensory block and numbness was significantly higher at both $10^{\text {th }}$ and $15^{\text {th }}$ minute in the patients of Group 2 compared with Group 1 (Table 1).

A noteworthy increase was determined in the degree of complete blockade in all nerve function at $10^{\text {th }}, 20^{\text {th }}$, and $30^{\text {th }}$ minute in Group 2 in comparison with Group 1 using modified Bromage Score.

There was no difference between groups in the duration of tourniquet or operation, presence of pain as a result of the tourniquet, ratio of tourniquet use, requirement for analgesic, or satisfaction of the surgeon with respect to the anesthetic method used. The duration of the process was notably longer in Group 1 than in Group 2. Moreover, the patients of Group 1 needed additional analgesic in the postoperative period significantly earlier then those of Group 2. Complete satisfaction with the method of anesthesia was significantly lower in Group 1. The ratio of those who preferred the same method of local anesthesia for another operation was also substantially lower in Group 1 in comparison with patients in Group 2 (Table 2).

The rate of regaining complete sensation (recovery) after sensory block at $2^{\text {nd }}, 4^{\text {th }}$, and $8^{\text {th }}$ hours was determined to be significantly higher in Group 1. However, there was no remarkable difference between the 2 groups in this rate at $24^{\text {th }}$ hour (Table $3)$. In addition, patients were evaluated at $2^{\text {nd }}, 4^{\text {th }}$, and $8^{\text {th }}$ hours to determine the length of time required to recover motor function after the blockade. The results revealed that the ratio of hand and finger mobilization was significantly higher in Group 1 ( $<<0.05)$ (Table 4).

MBP at the fifth minute was significantly higher in patients in Group 1 compared with Group 2 $(p<0.05)$; however, there was no significant difference in values collected at other time points. HR measurement was similar between the 2 groups.

\section{DISCUSSION}

There are a number of advantages to the use of regional local anesthesia, including continued an- 
TABLE 1. Sensory block level

Pinprick test

Time

(minutes)

Degree of

Group 1

Group 2

$\mathrm{p}$

sensation

$\begin{array}{llll}\mathrm{n} & \% & \mathrm{n}\end{array}$

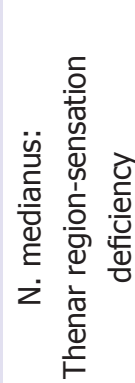

5

n $\%$

$5 \quad 10.0$

\begin{tabular}{cccccc} 
& No sensory block & 1 & 2.0 & 0 & 0.0 \\
\hline \multirow{3}{*}{10} & Numbness & 21 & 42.0 & 44 & 88.0 \\
\cline { 2 - 6 } & Moderate & 29 & 58.0 & 6 & 12.0
\end{tabular}

0.000

\begin{tabular}{cccccc} 
& No sensory block & 0 & 0.0 & 0 & 0.0 \\
\hline \multirow{3}{*}{15} & Numbness & 44 & 89.8 & 50 & 100.0 \\
\cline { 2 - 6 } & Moderate & 3 & 6.1 & 0 & 0.0 \\
& No sensory block & 2 & 4.1 & 0 & 0.0
\end{tabular}

0.020

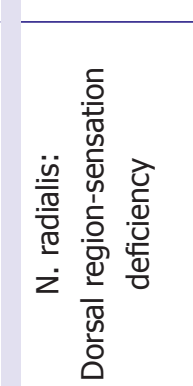

5

Numbness

$\begin{array}{cccc}1 & 2.0 & 5 & 10.0 \\ 48 & 96.0 & 45 & 90.0\end{array}$

0.092

0.000

\begin{tabular}{|c|c|c|c|}
\hline Numbness & 21 & 42.0 & 44 \\
\hline Moderate & 29 & 58.0 & 6 \\
\hline
\end{tabular}

\begin{tabular}{lllll} 
No sensory block & 0 & 0.0 & 0 & 0.0 \\
\hline
\end{tabular}

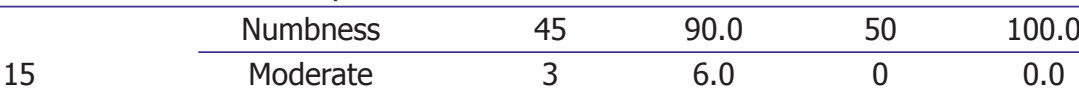

\subsection{2}

\begin{tabular}{|c|c|c|c|c|c|c|c|}
\hline & & No sensory block & 2 & 4.0 & 0 & 0.0 & \\
\hline \multirow{9}{*}{ 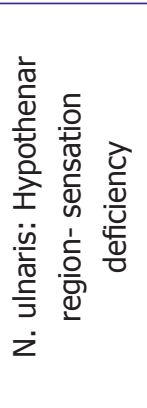 } & \multirow{3}{*}{5} & Numbness & 1 & 2.0 & 5 & 10.0 & \multirow[t]{3}{*}{0.092} \\
\hline & & Moderate & 48 & 96.0 & 45 & 90.0 & \\
\hline & & No sensory block & 1 & 2.0 & 0 & 0.0 & \\
\hline & \multirow{3}{*}{10} & Numbness & 21 & 42.0 & 44 & 88.0 & \multirow[t]{3}{*}{0.000} \\
\hline & & Moderate & 29 & 58.0 & 6 & 12.0 & \\
\hline & & No sensory block & 0 & 0.0 & 0 & 0.0 & \\
\hline & \multirow{3}{*}{15} & Numbness & 45 & 90.0 & 50 & 100.0 & \multirow[t]{3}{*}{0.022} \\
\hline & & Moderate & 3 & 6.0 & 0 & 0.0 & \\
\hline & & No sensory block & 2 & 4.0 & 0 & 0.0 & \\
\hline \multirow{9}{*}{ 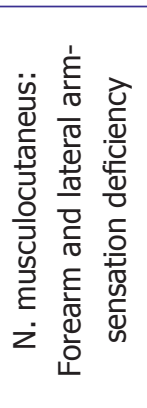 } & \multirow{3}{*}{5} & Numbness & 2 & 4.0 & 6 & 12.0 & \multirow[t]{3}{*}{0.140} \\
\hline & & Moderate & 47 & 94.0 & 44 & 88.0 & \\
\hline & & No sensory block & 1 & 2.0 & 0 & 0.0 & \\
\hline & \multirow{3}{*}{10} & Numbness & 21 & 42.0 & 44 & 88.0 & \multirow[t]{3}{*}{0.000} \\
\hline & & Moderate & 29 & 58.0 & 6 & 12.0 & \\
\hline & & No sensory block & 0 & 0.0 & 0 & 0.0 & \\
\hline & \multirow{3}{*}{15} & Numbness & 45 & 90.0 & 50 & 100.0 & \multirow[t]{3}{*}{0.022} \\
\hline & & Moderate & 3 & 6.0 & 0 & 0.0 & \\
\hline & & No sensory block & 2 & 4.0 & 0 & 0.0 & \\
\hline
\end{tabular}

Chi-square test.

algesia into the postoperative period and earlier mobilization of the patient than is the case with general anesthesia. Since the patient is conscious, they are able to respond and express any complaints 
TABLE 2. Characteristics of the procedures

\begin{tabular}{|c|c|c|c|c|c|c|c|}
\hline & \multicolumn{3}{|c|}{ Group 1} & \multicolumn{3}{|c|}{ Group 2} & \multirow[t]{2}{*}{$\mathrm{p}$} \\
\hline & Mean \pm SE & $\mathrm{n}$ & $\%$ & Mean \pm SE & $\mathrm{n}$ & $\%$ & \\
\hline Duration of process & $4.1 \pm 1.3$ & & & $2.2 \pm 1.3$ & & & 0.000 \\
\hline Duration of tourniquet & $50.7 \pm 19.2$ & & & $52.9 \pm 17.2$ & & & 0.343 \\
\hline Duration of operation & $57.0 \pm 24.9$ & & & $57.3 \pm 18.6$ & & & 0.395 \\
\hline \multicolumn{8}{|l|}{ Use of tourniquet } \\
\hline No & & 0 & 0.0 & & 1 & 2.0 & 1.000 \\
\hline Yes & & 50 & 100.0 & & 49 & 98.0 & \\
\hline \multicolumn{8}{|l|}{ Tourniquet pain } \\
\hline No & & 46 & 92.0 & & 46 & 92.0 & 1.000 \\
\hline Yes & & 4 & 8.0 & & 4 & 8.0 & \\
\hline $\begin{array}{l}\text { Time until requirement } f \\
\text { postoperative analgesic }\end{array}$ & $9.8 \pm 12.6$ & & & $337.0 \pm 168.7$ & & & 0.000 \\
\hline \multicolumn{8}{|c|}{ Peroperative complications } \\
\hline No & & 50 & 100.0 & & 50 & 100.0 & - \\
\hline Yes & & 0 & 0.0 & & 0 & 0.0 & \\
\hline \multicolumn{8}{|l|}{ Postoperative side effects } \\
\hline No & & 50 & 100.0 & & 50 & 100.0 & - \\
\hline Yes & & 0 & 0.0 & & 0 & 0.0 & \\
\hline \multicolumn{8}{|c|}{$\begin{array}{l}\text { Patient satisfaction with analgesic } \\
\text { agent application method }\end{array}$} \\
\hline Not satisfied & & 1 & 2.0 & & 0 & 0.0 & \\
\hline Moderately satisfied & & 6 & 12.0 & & 0 & 0.0 & 0.006 \\
\hline Satisfied & & 43 & 86.0 & & 50 & 100.0 & \\
\hline \multicolumn{8}{|c|}{$\begin{array}{l}\text { Surgeon satisfaction with local } \\
\text { anesthetic application method }\end{array}$} \\
\hline Not satisfied & & 2 & 4.0 & & 4 & 8.0 & \\
\hline Moderately satisfied & & 6 & 12.0 & & 0 & 0.0 & 0.218 \\
\hline Satisfied & & 42 & 84.0 & & 46 & 92.0 & \\
\hline \multicolumn{8}{|c|}{$\begin{array}{l}\text { Would you choose the same method } \\
\text { of local anesthetic application if } \\
\text { another operation is required? }\end{array}$} \\
\hline No & & 7 & 14.0 & & 0 & 0.0 & \\
\hline Yes & & 43 & 86.0 & & 50 & 100.0 & 0.006 \\
\hline
\end{tabular}

SE: Standard error. Chi-square test (or Fisher's exact test) / Mann-Whitney U test.

during the administration of anesthesia. Additionally, spontaneous respiration continues and airway reflexes are preserved [1]. For these and other reasons, with developments in advanced technology and modern local anesthetics, the use of regional anesthetic techniques has increased in recent years.

Advances in the use of US imaging led to a gen- eration of portable US units that have enabled enhanced use of regional local anesthesia. The achievement of nerve block increased while the ratio of complications decreased using US guidance $[2,3]$.

Hadzic et al. [4] compared general anesthesia with infraclavicular block in cases of hand surgery. They suggested that both the score of analgesia 
TABLE 3. Rate of sensory recovery

\begin{tabular}{|c|c|c|c|c|c|c|}
\hline & \multirow[t]{2}{*}{ Time (hours) } & \multicolumn{2}{|c|}{ Group 1} & \multicolumn{2}{|c|}{ Group 2} & \multirow[t]{2}{*}{$\mathrm{p}$} \\
\hline & & $\mathrm{n}$ & $\%$ & $\mathrm{n}$ & $\%$ & \\
\hline \multirow[t]{16}{*}{ Do you feel the touch? } & $2^{\text {nd }}$ hour & & & & & \\
\hline & No & 0 & 0 & 43 & 86 & \\
\hline & Moderate & 0 & 0 & 5 & 10 & 0.000 \\
\hline & Yes & 50 & 100 & 2 & 4 & \\
\hline & $4^{\text {th }}$ hour & & & & & \\
\hline & No & 0 & 0 & 20 & 40 & 0.000 \\
\hline & Moderate & 0 & 0 & 20 & 40 & \\
\hline & Yes & 50 & 100 & 10 & 20 & \\
\hline & $8^{\text {th }}$ hour & & & & & \\
\hline & No & 0 & 0 & 5 & 10 & 0.000 \\
\hline & Moderate & 0 & 0 & 7 & 14 & \\
\hline & Yes & 50 & 100 & 38 & 76 & \\
\hline & $24^{\text {th }}$ hour & & & & & \\
\hline & No & 0 & 0 & 1 & 2 & 0.315 \\
\hline & Moderate & 0 & 0 & 0 & 0 & \\
\hline & Yes & 50 & 100 & 49 & 98 & \\
\hline
\end{tabular}

Chi-square test.

TABLE 4. Rate of recovery of motor function

Time (hours)

$\frac{\text { Group } 1}{\mathrm{n} \quad \%}$

$\frac{\text { Group } 2}{\mathrm{n} \quad \%}$

Can you move your arm and fingers?

$\begin{array}{ccccc}2^{\text {nd }} \text { hour } & & & & \\ \text { No } & 0 & 0 & 42 & 84 \\ \text { Moderate } & 0 & 0 & 6 & 12 \\ \text { Yes } & 50 & 100 & 2 & 4 \\ 4^{\text {th }} \text { hour } & & & & \\ \text { No } & 0 & 0 & 9 & 18 \\ \quad \text { Moderate } & 0 & 0 & 21 & 42 \\ \text { Yes } & 50 & 100 & 20 & 40 \\ 8^{\text {th }} \text { hour } & & & & \\ \text { No } & 0 & 0 & 3 & 6 \\ \text { Moderate } & 0 & 0 & 5 & 10 \\ \text { Yes } & 50 & 100 & 42 & 84 \\ 2^{4 \text { th }} \text { hour } & & & & \\ \text { No } & 0 & 0 & 1 & 2 \\ \text { Moderate } & 0 & 0 & 1 & 2 \\ \text { Yes } & 50 & 100 & 48 & 96\end{array}$

0.000

0.000

42 40

6

0.003

84

2

0.495

96

Chi-square test. 
was better and that postoperative analgesic was not needed with infraclavicular block. They further reported that local anesthesia was better in terms of earlier ambulation and had fewer side effects.

In this study, we compared 2 methods that are frequently used in routine hand surgery: RIVA (Group 1) and US-guided infraclavicular brachial plexus block (Group 2). The aim of the research was to determine the most advantageous method of providing anesthesia in short-duration upper extremity surgery. The high success rate and ease of application observed led to a preference for infraclavicular block.

Advantages to the use of US in regional anesthesia include direct visualization of nerves and anatomical structures, making it easy to localize and follow the needle. Imaging of the distribution of the local anesthetic also allows for reduced dose and fewer needle attempts, which increases patient comfort. However, many aspects of the use and development of US-guided regional anesthesia have not yet been completely clarified. These include ideal needle position for a secure, successful block, the number of injections required for each block, minimal volume of local anesthetics, and whether it is preferable to an alternative anesthetic method in a particular procedure [5-8].

Successful application of regional anesthetic method depends on parameters including compatible timing between duration of operation and local anesthesia, selection of appropriate regional anesthetic method for targeted surgery, and the experience of the surgeon [9]. Important issues to be considered in cases using either RIVA or peripheric block include not exceeding toxic dose of local anesthetic and remaining alert for hemodynamic complications that may develop.

Research continues regarding reduction of the quantity and concentration of local anesthetic agents and determination of minimal volume and dose to avoid systemic effect. To improve the generation of sufficient anesthesia with low concentration and dose, various adjuvant drugs are added to local anesthetics. Numerous recent studies have examined the use of clonidine, morphine, meperidine, fentanyl, sufentanyl, tramadol, muscle relaxants, nonsteroid anti-inflammatory drugs, dexamethasone, magnesium, and other local anesthetics to promote the formation of sensory and motor block and improve the quality of anesthesia created with RIVA $[10,11]$. As a result of being able to see the drug injection site, quality anesthesia can be generated with lower doses of local anesthetic in USguided infraclavicular block without requiring any additional drugs. In this study, we did not use any drug other than local anesthetic agent; prilocaine was used at volume of $40 \mathrm{~mL}(3 \mathrm{mg} / \mathrm{kg})$ and $20 \mathrm{~mL}$ (1\%) in Group 1 and Group 2, respectively.

Local anesthetic agents used in regional anesthesia have some advantageous features, including prolonged and less toxic anesthetic effects [12]. The most commonly used agents in RIVA are lidocaine and prilocaine. Prilocaine is used at dose of 3-4 $\mathrm{mg} / \mathrm{kg}$ at a concentration ranging between $0.15 \%$ and $2 \%$ in RIVA. This anesthetic agent is commonly used in RIVA because of its rapid absorption by tissues and quick metabolization, reducing plasma concentration. The duration of the anesthetic effect of prilocaine is longer than that of lidocaine [13].

The duration of all application processes in this study was recorded by a person who was not involved in the research. Processing time was considered to be the length of time between the entry of the needle into the skin and exit of the needle after injection of local anesthetic agent in Group 2. In Group 1, processing time began with application of the Esmarch bandage and continued until the injection of the local anesthetic agent was completed. Processing time was significantly greater in Group 1

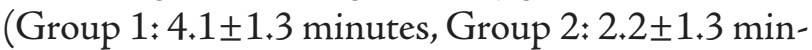
utes; $\mathrm{p}<0.05)$.

Gurkan et al. [14] and Uysal et al. [15] reported block processing time of brachial plexus by USguided infraclavicular approach of $24 \pm 1$ minutes and 5.2 minutes, respectively, while it was $3 \mathrm{~min}$ utes in a study conducted by Dingemans et al. [16]. Our research yielded a processing time of $3.7 \pm 2.6$ minutes.

Due to the need to apply an additional analgesic agent, 3 patients were excluded from the study. One 
other individual was excluded as a result of conversion to general anesthesia. Recovery from sensory block was determined significantly earlier in Group 1 at $2^{\text {nd }}, 4^{\text {th }}$, and $8^{\text {th }}$ hour compared with Group 2 $(\mathrm{p}<0.05)$. However, there was no difference between groups $24^{\text {th }}$ hour.

Postoperative analgesic was required by patients in Group 1 due to the development of pain 1 to 2 minutes after release of the tourniquet. The length of time until the first analgesic requirement was longer in Group $2(\mathrm{p}<0.05)$. This condition provides a significant advantage in terms of patient satisfaction. Moreover, it is interesting to note that it is also gratifying to the surgeon.

Evaluation of the length of time until full recovery from motor block and ratios of hand and finger movement ability were found to be significantly greater in Group 1 in comparison with Group 2 at $2^{\text {nd }}, 4^{\text {th }}$, and $8^{\text {th }}$ hours $(\mathrm{p}<0.05)$; however, this difference disappeared at $24^{\text {th }}$ hour $(p>0.05)$. Enhanced success ratio of achievement of block was seen in both groups (Group 1: 94.3\%, Group 2: 98.03\%). Sandhu et al. [17] described nearly 100\% achievement with an application of local anesthetic around the neural cord with US guidance.

There were no complications due to process in this study. Based on findings from magnetic resonance imaging, Neuburger et al. [18] suggested that infraclavicular block is a safe technique, although there is a risk for development of pneumothorax. Though this risk is small, pneumothorax is the most dangerous complication in infraclavicular brachial plexus block. An experienced surgeon should perform the block, complying with the rules and using suitable size nerve stimulator. The risk of pneumothorax is virtually eliminated in the application of the block with US guidance. Pneumothorax was not observed in any patient in our block groups.

Vascular puncture is a complication that may be encountered in brachial plexus block due to the close proximity of blood vessels and nerves. Incidence of this complication is reduced with use of US. No vascular puncture or invasive process was observed in the present study. The rate of vascular injury complication in peripheral nerve block guid- ed by US was determined to be $0.4 \%$ in large series of retrospective and prospective applications [17, 19]. The rate of vascular injury in a study comparing neurostimulation with US was found to be significantly lower in the US group [20,21]. Vascular puncture has been observed in US-guided infraclavicular block at rate of $0 \%$ to $7.5 \%$ [22-26].

In this study, we did not observe any side effects, toxicity, or complication during or after anesthesia in either group in terms of the application of local anesthetic agent. Both methods also demonstrated the effect of surgical anesthesia at the desired time. No pneumothorax, respiratory problems, or hematoma due to vascular puncture was found in subsequent patient controls.

Although both methods are used for upper extremity surgery, we conclude that US-guided infraclavicular block may be preferred for greater postoperative patient comfort in short-duration upper extremity surgery, particularly hand, wrist, and forearm operations. Although conventional methods, including RIVA, may still be used successfully, we think that infraclavicular brachial block is better than other methods due to the low risk and low rate of complications, as well as ease of application with current improvements in technology.

\section{Conflict of Interest: None declared.}

Financial Disclosure: The authors declared that this study has received no financial support.

Authorship contributions: Concept - Z.S., G.T.; Design Z.S., G.T.,O.E; Supervision - G.T., D.S., A.O., O.E.; Materials - Z.S., G.T., R.C.; Data collection \&/or processing - Z.S., R.C., D.S., G.O.; Analysis and/or interpretation - Z.S., G.T., A.O., O.E.; Literature search - Z.S., G.T, G.O.; Writing - Z.S., G.T., O.E.; Critical review - G.T., A.O.,O.E.

\section{REFERENCES}

1. Gürkan Y, Acar S, Solak M, Toker K. Comparison of nerve stimulation vs. ultrasound-guided lateral sagittal infraclavicular block. Acta Anaesthesiol Scand 2008;52:851-5.

2. Klaastad $\varnothing$, Smedby O, Thompson GE, Tillung T, Hol PK, Røtnes JS, et al. Distribution of local anesthetic in axillary brachial plexus block: a clinical and magnetic resonance imaging study. Anesthesiology 2002;96:1315-24.

3. Hadzic A, Arliss J, Kerimoglu B, Karaca PE, Yufa M, Claudio $\mathrm{RE}$, et al. A comparison of infraclavicular nerve block versus gen- 
eral anesthesia for hand and wrist day-case surgeries. Anesthesiology 2004;101:127-32.

4. Klaastad $\varnothing$, Smith HJ, Smedby O, Winther-Larssen EH, Brodal $\mathrm{P}$, Breivik $\mathrm{H}$, et al. A novel infraclavicular brachial plexus block: the lateral and sagittal technique, developed by magnetic resonance imaging studies. Anesth Analg 2004;98:252-6.

5. Heid FM, Jage J, Guth M, Bauwe N, Brambrink AM. Efficacy of vertical infraclavicular plexus block vs. modified axillary plexus block: a prospective, randomized, observer-blinded study. Acta Anaesthesiol Scand 2005;49:677-82.

6. Marhofer P, Greher M, Kapral S. Ultrasound guidance in regional anaesthesia. Br J Anaesth 2005;94:7-17.

7. Koscielniak-Nielsen ZJ, Rasmussen H, Hesselbjerg L, Nielsen TP, Gürkan Y. Infraclavicular block causes less discomfort than axillary block in ambulatory patients. Acta Anaesthesiol Scand 2005;49:1030-4.

8. Gürkan Y, Ozdamar D, Hoşten T, Solak M, Toker K. Ultrasound guided lateral sagital infraclavicular block for pectoral flap release. Agri 2009;21:39-42.

9. Brown DL. Brachial plexus anesthesia: an analysis of options. Yale J Biol Med 1993;66:415-31.

10. Kleinschmidt S, Stöckl W, Wilhelm W, Larsen R. The addition of clonidine to prilocaine for intravenous regional anaesthesia. Eur J Anaesthesiol 1997;14:40-6.

11. Turan A, Memiş D, Karamanlioğlu B, Güler T, Pamukçu Z. Intravenous regional anesthesia using lidocaine and magnesium. Anesth Analg 2005;100:1189-92.

12. Whiteside JB, Wildsmith JA. Developments in local anaesthetic drugs. Br J Anaesth 2001;87:27-35.

13. Sean JE, Vonda B, Cephas PS. Intravenous regional anesthesia: a reviev. Seminars in Anesthesia. Perioperative Medicine and Pain 1998;1:2-9.

14. Gürkan Y, Tekin M, Acar S, Solak M, Toker K. Is nerve stimulation needed during an ultrasound-guided lateral sagittal infraclavicular block? Acta Anaesthesiol Scand 2010;54:403-7.

15. Yarkan Uysal H, Acar HV, Tezer E, Ceyhan A, Dikmen B. Ultrasonography (us) guidance in infraclavicular block: comparison of us vs. us + neurostimulation in a prospective, randomised study. Journal of Anesthesia 2013;21:106-12.

16. Dingemans E, Williams SR, Arcand G, Chouinard P, Harris P, Ruel M, et al. Neurostimulation in ultrasound-guided infra- clavicular block: a prospective randomized trial. Anesth Analg 2007;104:1275-80.

17. Sandhu NS, Manne JS, Medabalmi PK, Capan LM. Sonographically guided infraclavicular brachial plexus block in adults: a retrospective analysis of 1146 cases. J Ultrasound Med 2006;25:1555-61.

18. Neuburger M, Kaiser H, Uhl M. Biometric data on risk of pneumothorax from vertical infraclavicular brachial plexus block. A magnetic resonance imaging study. Anaesthesist 2001;50:511-6.

19. Sites BD, Spence BC, Gallagher JD, Wiley CW, Bertrand ML, Blike GT. Characterizing novice behavior associated with learning ultrasound-guided peripheral regional anesthesia. Reg Anesth Pain Med 2007;32:107-15.

20. Kapral S, Krafft P, Gosch M, Fleischmann D, Weinstabl C. Ultrasound imaging for stellate ganglion block: direct visualization of puncture site and local anesthetic spread. A pilot study. Reg Anesth 1995;20:323-8.

21. Liu FC, Liou JT, Tsai YF, Li AH, Day YY, Hui YL, et al. Efficacy of ultrasound-guided axillary brachial plexus block: a comparative study with nerve stimulator-guided method. Chang Gung Med J 2005;28:396-402.

22. Brull R, Lupu M, Perlas A, Chan VW, McCartney CJ. Compared with dual nerve stimulation, ultrasound guidance shortens the time for infraclavicular block performance. Can J Anaesth 2009;56:812-8.

23. Sauter AR, Dodgson MS, Stubhaug A, Halstensen AM, Klaastad $\varnothing$. Electrical nerve stimulation or ultrasound guidance for lateral sagittal infraclavicular blocks: a randomized, controlled, observer-blinded, comparative study. Anesth Analg 2008;106:1910-5.

24. Marhofer P, Sitzwohl C, Greher M, Kapral S. Ultrasound guidance for infraclavicular brachial plexus anaesthesia in children. Anaesthesia 2004;59:642-6.

25. Frederiksen BS, Koscielniak-Nielsen ZJ, Jacobsen RB, Rasmussen H, Hesselbjerg L. Procedural pain of an ultrasound-guided brachial plexus block: a comparison of axillary and infraclavicular approaches. Acta Anaesthesiol Scand 2010;54:408-13.

26. Vainionpää VA, Haavisto ET, Huha TM, Korpi KJ, Nuutinen LS, Hollmén AI, et al. A clinical and pharmacokinetic comparison of ropivacaine and bupivacaine in axillary plexus block. Anesth Analg 1995;81:534-8. 